\title{
A Worldwide State-of-the-Art Analysis for Bus Rapid Transit: Looking for the Success Formula
}

\author{
Dr. Alexandros Nikitas and Prof. MariAnne Karlsson \\ Chalmers University of Technology, Gothenburg, Sweden
}

\begin{abstract}
This paper's intended contribution, in terms of providing an additional angle in the existing Bus Rapid Transit (BRT) state-of-the-art knowledge spectrum, is a dual one. On the one hand, it provides a detailed description of the mode, re-defining BRT as an overall concept by identifying, discussing, and categorizing in a systematic way its strengths and its weaknesses in comparison with rail-based solutions and conventional bus services. On the other hand, it presents in detail a number of selected scheme-oriented applications from around the world, looking into some of the basic ingredients behind BRT's success (or failure) stories. This is a scientific effort that could inform the reader about the current status of BRT internationally and about the challenges and opportunities that exist when trying to materialize $B R T$ 's potential as an effective urban passenger solution that could challenge the merits of more conventional mass-transit options.
\end{abstract}

\section{Introducing Bus Rapid Transit}

Bus Rapid Transit (BRT) is a modern breed of urban passenger transportation with a consistently growing global importance due to evidence of an ability to implement mass transportation capacity quickly and at a low-to-moderate cost (Deng and Nelson 2011). Perhaps the most complete and focus-driven definition of what BRT intends to be is the one addressing it "as a rubber-tyred rapid transit service that combines stations, vehicles, running ways, a flexible operating plan, and technology into a high quality, customer focused service that is frequent, fast, reliable, comfortable and cost efficient" (Canadian Urban Transit Association 2004).

More specifically, BRT refers to schemes that apply rail-like infrastructure and operations to bus systems in expectation of offerings that can include high service levels, segregated rights-of-way, station-like platforms, high-quality amenities, and intelligent transport systems for a fraction of the cost of fixed rail (Currie and Delbosc 2011). This cautious phrasing means that BRT "does not necessarily represent transformation as such, but a means to achieve transformation" (Mejia-Dugand et al. 2013). A combination of infrastructure 
and service-oriented elements that, in principle, mean to bridge together the best that light rail and buses have to offer is the prerequisite to forming mass transit systems capable of responding to rapidly-changing mobility needs with a strong positive identity that evokes to a unique image (Levinson et al. 2003).

BRT applications are designed to be appropriate to the markets they serve and their physical surroundings, and they can be incrementally implemented in a variety of settings and types. Because of the inherent flexibility advantages of rubber-tired buses-e.g., unlike rail systems, the same vehicle that functions as a line-haul carrier also can morph into a neighborhood feeder-BRT also is suited for many lower-density areas (Cervero and Kang 2011). However, the vast potential of BRT could be used at its maximum rate in congested urban environments where adequate mass transit services could not be provided to road users by (or solely by) more expensive modal options such as light rail or metro.

BRT, thus, is a homogeneous system of facilities, services, and amenities that has the potential to become an alternative far more competitive to car-oriented mobility than conventional buses, to the degree that it could redefine the very identity of a city.

A BRT system is composed of the following ingredients:

- Vehicles, which not only contribute significantly to BRT's image and identity, but also play a strong role in achieving measurable performance success (Zimmerman and Levinson 2004)

- Stops, stations, terminals, and corridors, which define the system's area of operation

- A wide variety of rights-of-way, including bus priority in signalized intersections, dedicated lanes on surface streets, and, more importantly, special BRT busways completely separated from road traffic; BRT routes can be operated almost anywhere-on abandoned rail lines, within a highway median, or on city streets (Jarzab et al. 2002)

- Pre-board fare collection, to disengage ticketing from the on-board user experience and to provide a hypothecation mechanism for the system's long term viability

- The use of information and communication technologies, to improve the quality of the services provided in terms of customer convenience, speed, reliability, integration, and safety

- All-day service that, according to Levinson et al. (2003), should operate at least 16 hours per day with peak headways of 10 minutes or less

- Brand identity, consisting of perceptual constructs substantiated by the strategic deployment, placement, and management of communication elements that allow people to recognize the unique qualities of a specific BRT system; these include visual and nominal identifiers (e.g., system name and logo), a color palette, and long-term strategic marketing and advertising plans (Hess and Bitterman 2008)

For the economy of the overall transport system of a city that employs BRT, some of the infrastructure facilities (e.g., busways and stationary settings) could be shared with light 
rail transit systems (with no loss of performance to either). In other instances, BRT can allow conventional bus services to access certain key sections of its infrastructure, allowing for bus-based service integration (Deng and Nelson 2011). BRT systems also can operate in mixed traffic flow when physical, traffic, and/or environmental factors preclude bus lanes or busways from being implemented-something that could lead to decreased bus speeds and service reliability and be a setback for the system's image. However, there are serious trade-offs with implementing BRT in mixed traffic flow; advantages include low costs and fast implementation with a minimum of construction (Miller 2009). Therefore, the amount of dedicated runway for a BRT system is a strategic decision that depends on the city hosting the scheme and the city's unique geographical, socio-economic, and transport-related characteristics.

$\mathrm{BRT}$, nonetheless, is a very demanding transport option that could change the balance of a whole transport network within a city. This is because BRT would re-orient significantly something as limited and precious as road space provision in favor of bus services. This obviously will impact the rest of the road traffic in a severe way in case a decisive modal shift would not be achieved. It should be noted that BRT is not suitable for every city. There are population and topological criteria and thresholds that justify the implementation and the magnitude of such a scheme.

BRT systems have been approached from an institutional perspective (Filipe and Macario 2013; Lámbarry Vilchis et al. 2010), a social perspective (Delmelle and Casas 2012; Lin and Wu 2007), an economic perspective (Cervero and Kang 2011; Hensher and Golob 2008; Lindau et al. 2008), an urban planning perspective (Gómez 2004), an environmental perspective (Wöhrnschimmel et al. 2008), and a technical perspective (Hensher and Golob 2008; Hidalgo et al. 2012). All these authors agree that the BRT concept could be a feasible solution for many cities' mobility problems and, furthermore, that 'there is a lack of studies analyzing the connection among the implementing venues, the transmission of ideas from one to the other, and the impact that incremental improvements have had on the geographical expansion of the concept" (Mejia-Dugand et al. 2013). Thus, any work concentrating on such issues could be a timely and meaningful process adding to the existing BRT knowledge.

\section{The Advantages of BRT}

BRT has been widely regarded as "one of the most wide-spread urban public transportation revolutions" of recent decades (Jiang et al. 2012; Levinson et al. 2003). This is because BRT is a mass transit choice with considerable advantages in terms of its implementation merits but also because of its vast potential to eventually benefit in a variety of ways the urban environment for which it has been chosen. Wright and Hook (2007) and Hensher (1999) support the view that BRT is a transport mode rapidly expanding around the world because of its 1) low cost, 2) operating flexibility, 3) rapid implementation, and 4) high performance (i.e., reliability/speed) and impact (i.e., user satisfaction/environmental benefits). Based on a study by the Canadian Urban Transit Association (2004), Hensher and Golob (2008) also report as BRT advantages over other mass transit systems the potential for greater patronage and higher capacities, the possibility of incremental implementation, and the induction of land use changes. However, it has been well documented by 
international experience, thus far, that all these advantages are not necessarily true for every BRT case (Filipe and Macario 2013).

The first significant advantage of BRT over rail-based transit options is that it needs considerably lower start-up capital investment while operational costs are moderate (Badami and Haider 2007; Campbell 2009; Hensher and Golob 2008). System costs are a fraction of those of comparable rail systems (Currie and Delbosc 2011; Hidalgo and Gutierrez 2013). Hodson et al. (2013) reported that the main antagonists of BRT, which are light rail systems when compared to bus-oriented schemes in purely economic terms, were found to be:

- too costly

- poor in terms of financial performance

- in need of significant local funding in addition to central government funding to become a reality

Figure 1 shows the capital costs per kilometer for selected BRT corridors around the globe. These costs range from the very moderate $\$ 1.4$ million per kilometer for the scheme in Jakarta to Bogotá's $\$ 12.5$ million per kilometer. ${ }^{1}$ Rail systems with similar capacities cost 3 to 10 times more (Hensher 1999; Wright and Hook 2007).

FIGURE 1.

Capital costs per kilometer for selected BRT systems

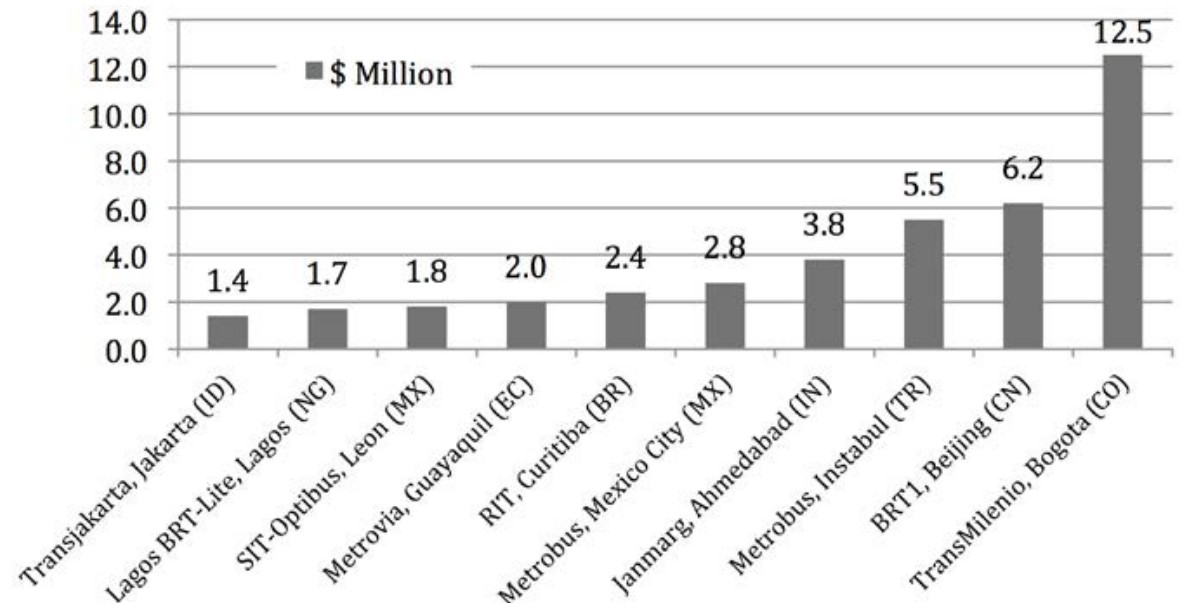

Source: Hidalgo and Carrigan 2010

The system in Bogotá is considerably more expensive because it includes dual lanes, large stationary facilities, and some non-grade intersections, as well as a large fleet of articulated and bi-articulated buses, to provide for very high capacity and high commercial speeds (Hidalgo and Gutierrez 2013).

\footnotetext{
1 These costs have not been adjusted to reflect inflation since the time of construction, the differences in labor costs in different regions of the world, and the differences in the nature and extent of planning studies required in various countries because BRT-related expenditure figures are extremely difficult to locate in a form that could be treated accordingly. Rather, these costs are indicative numbers given by the operators but could nonetheless allow rough comparisons between schemes.
} 
Overall, accessing information about BRT costs is neither an easy nor a straightforward task. In many cases, capital costs for specific BRT applications are fully integrated in much broader transport improvement packages, and identifying the specific BRT-related figures is near to impossible. For instance, the TranSantiago project has three main components: the development of a BRT network, the expansion of the existing metro system, and the integration across all transit modes in the city. The initial conceptual framework, estimated at $\$ 250$ million, was later revised to incorporate an extensive expansion of the metro network with total capital costs of almost $\$ 2.5$ billion. No specific information solely related to the TranSantiago BRT framework per se is available.

Compared with other forms of mass transit, BRT systems are more flexible. The fact that BRT systems have the potential to use the same operating infrastructure that could have been already in place for light rail transit systems and, at the same time, allow conventional bus services to access certain BRT infrastructure sections to facilitate interconnection and performance enhancement (Deng and Nelson 2011) underlines the interoperability dynamics of this mode. Because BRT vehicles are rubber-tired, they can operate in a wide range of environments without forcing transfers or requiring expensive running way construction over the entire range of their operation. Through this flexibility, BRT can serve a geographic range much wider than that in which dedicated BRT guideways do exist (Levinson et al. 2002). BRT also may be implemented in combination with a variety of travel demand management measures, such as congestion charging or traffic calming. Moreover, BRT can be more adaptable to deal with changing travel patterns and is faster to build than any rail-based scheme.

The capability of BRT to be implemented rapidly make this type of system attractive to political leaders willing to complete systems before the next election cycle (Hidalgo and Carrigan 2010). In comparison, the planning timescales and consultation processes for rail-based systems are excessively long, and this is a key reason that a number of these schemes have failed already in the planning stages (Hodgson et al. 2013). When there was a clear BRT vision by a local champion or any other political leader, planning for implementation received priority and development cycles were short, at least for the initial phases of project implementation (Hidalgo et al., 2007). For instance, the city of Guadalajara, Mexico, completed a high-quality corridor $16 \mathrm{~km}$ long for 125,000 passengers per day in only 2 years from idea to implementation (Hidalgo et al. 2010). The successes of BRT in Curitiba, Bogotá, Guangzhou, Istanbul, and elsewhere also are helping decisionmakers in developing cities to adopt BRT concepts, although implementation in developed countries has been slower than elsewhere due to preferences of planners and decisionmakers for rail systems and also due to compliance with planning and funding regulations, including extensive public participation processes (Hidalgo and Gutierrez 2013).

Case studies summarized by Levinson et al. (2003) and Wright and Hook (2007) suggested that BRT could be the most cost-effective way of providing a high-performance public transit. The main indicators of performance of a BRT scheme are commercial speed, capacity, and productivity (Hidalgo and Gutierrez 2013). The qualities represented by these indicators are supported by special design features that BRT schemes offer. These operational features that can define the individual quality and performance potential of any local BRT application are described by the BRT Standard, a comparison tool meant 
to assign points to BRT systems according to their serviceability. High points mean that a system is in line with international BRT best practice. The assessed aspects that are being considered in the latest BRT Standard designed from the Institute for Transportation and Development Policy (ITDP 2014) include:

- BRT basics (dedicated right-of-way, busway alignment, off-board fare collection, intersection treatment, platform-level boarding)

- Service planning (multiple routes, express/limited/local services, control center, located in top 10 corridors, demand profile, hours of operations, multi-corridor network)

- Infrastructure (passing lanes, bus emissions minimization, stations set back from intersections, center stations, pavement quality)

- Stations (distance between stations, safe and comfortable stations, number of doors on bus, docking bays and sub-stops, sliding doors in BRT stations)

- Communications (branding, passenger information)

- Access and integration (universal access, integration with other public transport, pedestrian access, secure bicycle parking, bicycle lanes, bicycle-sharing integration)

Point deduction also exists that penalize BRT schemes for poor performance in commercial speeds, service capacity, lack of enforcement of right-of-way, significant gap between bus floor and station platform, overcrowding, poor infrastructure maintenance, and lowpeak and off-peak frequencies (ITDP 2014).

Regarding BRT transport-related impacts, most systems have showed better performance than the bus operations they replaced regarding passenger demand, user satisfaction, travel time, and reliability (Diaz and Hinebaugh 2009; Gutierrez 2010; Wright and Hook 2007). Currie and Delbosc (2011) report that BRT technologies not only improve service design compared to conventional bus services but could potentially act as door openers to increased ridership because of:

- their higher frequency and longer operating hours services

- their priority systems, which are known to reduce journey times and improve service reliability

- their better-defined network/corridors, branding, and provision of new technology information systems to improve the ease of understanding the system

An additional, positive impact related to BRT systems, which has been documented by international practice, is the improvement of environmental conditions in terms of air quality, noise reduction, and energy consumption; also, externalities such as traffic accidents have been reduced considerably. Moreover, when looking at the broader picture on a longer-term basis, one could suggest that some BRT projects, and especially those that have received significant capital investments, may have the potential to bring broader effects on urban economic, social, and environmental development (Deng and Nelson 
2013) or at least deliver to the cities hosting them improved and more aesthetically-pleasing urban environments in which their societies can live.

It is arguable that BRT systems have been considered catalysts for land development in cities, such as Curitiba, Ottawa, Guadalajara, Guangzhou, and, to a lesser degree, Istanbul (Deng and Nelson 2011). Since proximity to mass transit can greatly save time and money costs of commuting, properties near transport facilities generally become desirable for new development or re-development. As reported by Deng and Nelson (2011), there is a growing body of evidence suggesting that BRT systems increase land values and, in some cases, successfully promote high-density residential, office, and commercial land use. Perk et al. (2013) report, for example, that the BRT stations located along Washington Street in Boston, where the Silver Line BRT operates, had a considerable impact on the rise in property market values, quite similar to that of light rail transit projects. Also, a detailed analysis on the impact of BRT on residential rents provided evidence showing that accessibility to BRT stations is associated with high value of residential properties (Rodríguez and Targa 2004).

\section{The Problems with BRT}

BRT is connected to a complex set of actors and networks within the social and technical dimensions of the city (Mejia-Dugand et al. 2013) and, thus, it is a system that could be difficult to implement and operate in a flawless manner. Filipe and Macario (2013) report that neither are all the advantages of BRT over other public transport modes always true, nor are the stories of implementing BRT systems always successful ones.

There are reports of BRT systems that fail to fulfill their objectives and have produced costly, in societal terms, side-effects-for example, the TranSantiago BRT system (in Chile) and its initial implementation. The system's performance (even now), belying expectations, has been rather dismal, making it a traumatic process for the whole of Chile, to the extent that taboo policy discussions such as nationalizing or subsidizing the public transport of the country became mainstream (Muñoz and Gschwender 2008).

BRT systems do not have a single meaning and image; on the contrary, they reflect a broad spectrum of applications, spanning from supporting mechanisms that simply provide infrastructure or marketing improvements to existing bus services operating on mixed traffic to totally segregated systems. There is a need, thus, to refine the definition of BRT and BRT-like systems and create categories based on objective performance measures to improve the understanding among planners and decisionmakers (Hidalgo and Gutierrez, 2013). Notwithstanding the growing evidence that BRT could serve, if well-planned and well-executed, as a viable transport "savior," pro-rail attitudes are still dominant in the public debate regarding best public transportation practice. BRT systems are still often regarded as "second best to rail-based alternatives," even if this is not justified by an explicit evaluation analysis (Finn et al. 2011; Gutierrez 2010; Hensher 1999).

Despite the growing acceptance that BRT is a time-efficient mode to implement in urban environments that face rapidly-growing mobility needs (Badami and Haider 2007; Hensher and Golob 2008), especially in comparison with fixed rail schemes, the political economy is often favorable to those candidates offering rail alternatives as part of their 
proposals in electoral debates (Hidalgo and Gutierrez 2013). BRT is, aside from the evidence provided to the contrary by Deng and Nelson (2011), still considered inadequate to foster urban development, and planners often cite this as a fact (Hidalgo and Gutierrez 2013). This is because the flexibility that enables BRT to be implemented in a wide range of environments-one of the system's main advantages-is also one of its weaknesses since a bus service is generally perceived as being less permanent than a rail service. Local decisionmakers and transport planners may, based on this very reason, question its ability to stimulate land development. However, there is insufficient evidence, especially in developed countries, to prove that development is favored by rail over high-quality bus systems (Hidalgo and Gutierrez 2013). In addition, the fact that BRT is being prioritized over any other road-based transport mode is perceived negatively by car users, who tend to think that road space is reduced, even though, at least in theory, road capacity means to be increased significantly.

The fact that BRT is cheaper to implement than a rail system does not mean that this is not a capital-intensive system (Deng and Nelson 2011). On the contrary, BRT is far more expensive than any conventional bus system that lacks sophisticated design features and the need for dedicated road space. Actually, funding for some cities that introduced BRT in the past was so scarce that the cities needed to rely on donations, budget allocations from the national governments, and loans. The process of applying for funding could be time-consuming as well, reducing the time window for the actual project implementation (Hidalgo et al. 2007).

In addition, several BRT systems in developing countries suffer problems such as the following (see also Hidalgo and Gutierrez 2013; Hidalgo and Carrigan 2010; Hidalgo et al. 2007):

- Rushed implementation - several components could be incomplete at the time of commissioning, but gradual improvement over time has been observed

- Tight financial planning - systems usually do not receive operational subsidies; there are exceptions, however, such as TranSantiago

- Very high vehicle occupancy levels - six to seven standees per $\mathrm{m}^{2}$, which is quite frequent nowadays and can make the user experience unpleasant

- Early deterioration of infrastructure - lack of road surface reinforcement or problems in design and construction result in maintenance issues

- Delayed implementation of fare collection systems - often requiring longer timetables than initially expected and very tight supervision

- Poor communication during disruptions caused by construction - can erode public support for the project, and insufficient user information and education prior to the system launch can lead to chaotic conditions or even protests (Carrigan et al. 2011)

- Integration deficiencies - for instance, in any urban transit system, the walking catchment area tends to be particularly important since walking is typically the primary access mode for urban stations (Hsiao et al. 1997); nonetheless, the reality is 
that accessing BRT stations is not as easy or safe as it should have been (unpublished research by the authors and some of their students shows that providing better pedestrian safety is a significant issue for some BRT applications in China)-this creates a serious integration issue that could adversely influence ridership numbers

These problems are associated with financial restrictions and institutional constraints, rather than intrinsic issues of BRT system concepts. Actually, many of them are local problems with unique topological character that could not be duplicated by similar schemes elsewhere. Nevertheless, these difficulties could influence to a certain point public attitudes reflecting the social acceptance of BRT.

Finally, the critics of BRT often cite comfort issues when comparing bus systems with rail. As a matter of fact, many past studies have found that, other things being equal, most public transport users prefer rail to bus because of its greater comfort (Abelson 1995). Due to the fact that most BRT systems in developing countries use very high occupancy standards, as a result of financial restrictions that would allow the provision of a level of service exceeding what customer fares can strictly finance for operation and vehicles, the standard of comfort can be neglected (Hidalgo and Carrigan 2010). However, Currie (2005) documents that there is actually evidence to support the fact that BRT has generally similar performance to light rail in the perceptions of passengers regarding comfort. Indeed, the average results of his study suggest that BRT may perform as well as rail with the other factors identified, depending on the scale of the BRT system and the quality of its stations and facilities.

Table 1 is a synopsis of the strengths and weaknesses and the opportunities and challenges that BRT represents today. ${ }^{2}$ It is a practical framework that looks into BRT from six different angles that refer to realistic concerns regarding BRT's actual use: 1) economy, 2) technology, 3) flexibility, 4) implementation, 5) performance, and 6) impact.

\footnotetext{
${ }^{2}$ The authors recognize that some of strengths and weaknesses presented in Table 1 are of a broader nature and, thus, could be in some degree applicable or could be generalized to other mass-transit modes.
} 
TABLE 1. Synopsis of Strengths and Weaknesses of BRT Today

\begin{tabular}{|c|c|c|c|}
\hline & & BRT Strengths & BRT Weaknesses \\
\hline \multirow{3}{*}{ Economy } & Cost & Moderate in comparison with rail-based schemes & More expensive than conventional bus services \\
\hline & Funding & $\begin{array}{l}\text { Moderate difficulties in allocating funds for building a BRT } \\
\text { scheme in comparison with rail-based schemes }\end{array}$ & $\begin{array}{l}\text { Could be still difficult to allocate; may be need for loans, donations, and support from } \\
\text { central government }\end{array}$ \\
\hline & Financial Planning & Good fare policy could allow schemes to be profitable & Tight, as systems usually do not receive operational subsidies \\
\hline \multirow{3}{*}{ Technology } & ICT & $\begin{array}{l}\text { Improves quality of services provided in terms of customer } \\
\text { convenience, speed, reliability, and safety }\end{array}$ & Advanced technology could be perceived as expensive addition to costly system \\
\hline & Pre-board Fare Collection & $\begin{array}{l}\text { Disengages ticketing from on-board user experience and } \\
\text { provides hypothecation mechanism for system's long term } \\
\text { viability }\end{array}$ & Challenging to achieve in initial phases and in need of very tight supervision thereafter \\
\hline & Priority Systems & Reduce journey times and increase reliability & $\begin{array}{l}\text { Could be viewed especially by car users as a "threat to their rights," thus reducing public } \\
\text { acceptability of BRT }\end{array}$ \\
\hline \multirow{2}{*}{ Flexibility } & Operational Flexibility & $\begin{array}{l}\text { Can operate everywhere, no need for exclusive use of } \\
\text { infrastructure }\end{array}$ & Could be viewed as proof that this is not permanent solution but temporary adjustment \\
\hline & Integration Flexibility & Can co-exist with metro, light rail, and conventional buses & $\begin{array}{l}\text { Can be seen as supplementary service to others and not as a primary transport solution; } \\
\text { integration deficiencies with other modes have been reported for existing schemes }\end{array}$ \\
\hline \multirow{4}{*}{ Implementation } & Rapid Implementation & $\begin{array}{l}\text { No need for long consulting and funding allocation processes } \\
\text { associated with rail operations }\end{array}$ & $\begin{array}{l}\text { Could lead to rushed implementation in which several components could be incomplete } \\
\text { at time of commissioning }\end{array}$ \\
\hline & $\begin{array}{l}\text { Straightforward } \\
\text { Implementation }\end{array}$ & $\begin{array}{l}\text { Can make this type of system attractive to cities and their } \\
\text { political leaders }\end{array}$ & $\begin{array}{l}\text { Can make BRT look like a project "too easy to deliver" in comparison with rail-based; } \\
\text { thus, could be falsely perceived as marginal transport improvement, something that } \\
\text { could be viewed as a disadvantage for ambitious politicians }\end{array}$ \\
\hline & Road-User Engagement & $\begin{array}{l}\text { Better-defined network/corridors, branding, and provision } \\
\text { of new technology information systems to improve ease of } \\
\text { understanding system }\end{array}$ & $\begin{array}{l}\text { Insufficient user information/education and poor communication during disruptions } \\
\text { caused by construction can diminish public trust to BRT }\end{array}$ \\
\hline & Political Leadership & $\begin{array}{l}\text { A strong political champion can be an asset in development and } \\
\text { implementation of BRT }\end{array}$ & When strong political support is not obvious, BRT planning could be highly problematic \\
\hline \multirow{4}{*}{ Performance } & High Capacity & Can be "real mass transit" solution & Very high occupancy standards could downgrade quality of service \\
\hline & High Speed & Some BRT schemes have comparable standards to metro & Some schemes only marginally improved conventional bus travel speeds in cities \\
\hline & High Reliability & Big improvement over conventional buses & $\begin{array}{l}\text { Is BRT that much more reliable from conventional buses to invest so many funds? Are } \\
\text { time savings really enough? }\end{array}$ \\
\hline & Comfort & $\begin{array}{l}\text { Argued that comfort is comparable to that provided by rail } \\
\text { services }\end{array}$ & Can be argued that comfort is not up to standards of comparable rail services \\
\hline
\end{tabular}


TABLE 1. Synopsis of Strengths and Weaknesses of BRT Today (cont.)

\begin{tabular}{|c|c|c|c|}
\hline & & BRT Strengths & BRT Weaknesses \\
\hline \multirow{6}{*}{ Impact } & Environment & $\begin{array}{l}\text { Improvement of environmental conditions in terms of air quality, } \\
\text { noise reduction, and energy consumption }\end{array}$ & Can be argued that metro/light rail are even greener \\
\hline & Traffic Safety & Reduction in number of traffic accidents & $\begin{array}{l}\text { Still not entirely disengaged by general road traffic; implies that there are still traffic } \\
\text { accidents related to its use }\end{array}$ \\
\hline & User Satisfaction & Majority of BRT users have been fairly satisfied with service & $\begin{array}{l}\text { Car users tend not to see significant BRT-related benefits, while some schemes have } \\
\text { been deemed poor by their users }\end{array}$ \\
\hline & Image & $\begin{array}{l}\text { With right patronage and political support, can become iconic } \\
\text { for respective cities }\end{array}$ & $\begin{array}{l}\text { Needs support to be publicly recognized as system much more complete and superior } \\
\text { than slightly improved conventional bus service }\end{array}$ \\
\hline & Urban Development & $\begin{array}{l}\text { May have potential to bring broader economic, social, and } \\
\text { environmental benefits on urban development }\end{array}$ & $\begin{array}{l}\text { Can be argued that BRT's potential for positive societal impacts is not as significant as } \\
\text { the potential of fixed-rail }\end{array}$ \\
\hline & Land Use & $\begin{array}{l}\text { Can increase land values, rent values, and even promote high- } \\
\text { density residential, office, and commercial land use }\end{array}$ & Metro and light rail could have an even greater positive land use impact \\
\hline
\end{tabular}




\section{An Introductory Review of BRT Systems Globally}

The development of BRT systems worldwide has witnessed tremendous growth in recent years (Delmelle and Casa 2012). Following a few pioneering implementations in the later 20th century, BRT has emerged as a leading mode of urban passenger transit in the first decade of the 21st century (Deng and Nelson 2011). Many of these new implementations are taking place in cities throughout the developing world, attributed largely to the relative inexpensive cost, easier implementation, and greater flexibility as compared to rail systems, and their promise to foster economic revitalization (Levinson et al. 2003).

TABLE 2.

Basic Review of Bus Rapid Transit per Continent

\begin{tabular}{|l|r|r|r|}
\hline \multicolumn{1}{|c|}{ Regions } & \multicolumn{1}{c|}{ Passengers/Day } & No. of Cities & \multicolumn{1}{c|}{ Length (km) } \\
\hline Africa & $242,000(0.76 \%)$ & $3(1.61 \%)$ & $80(1.68 \%)$ \\
\hline Asia & $8,529,322(26.93 \%)$ & $38(20.43 \%)$ & $1,317(27.68 \%)$ \\
\hline Europe & $1,804,829(5.69 \%)$ & $53(28.49 \%)$ & $822(17.27 \%)$ \\
\hline Latin America & $19,769,380(62.42 \%)$ & $60(32.25 \%)$ & $1,646(34.6 \%)$ \\
\hline Northern America & $894,821(2.82 \%)$ & $26(13.97 \%)$ & $798(16.77 \%)$ \\
\hline Oceania & $430,041(1.35 \%)$ & $6(3.22 \%)$ & $94(1.97 \%)$ \\
\hline
\end{tabular}

Source: www.brtdata.org, December 2014

Currently, there are 186 cities in 41 countries with BRT systems or corridors, serving almost 32 million passengers every day (www.brtdata.org, December 2014). New BRT systems and BRT extensions are under development as well.

The most important point of reference for BRT systems worldwide is South America, the birthplace of this mass transit mode. The South American schemes are widely appreciated as the most advanced and widely-used BRT systems in the world and provide a vision of how BRT can be used to radically change urban modal split in favor of public transportation. More specifically, BRT schemes have been implemented in 60 different locations in South America, hosting 62.4 percent of global BRT passenger trips (as of December 2014).

Recently, several cities in Asia have adopted BRT operations. The potential for BRT implementation in Asia is still huge, but this has been recognized only recently by Asian policymakers. Actually, the newer cities joining the list of the urbanities with BRT corridors are concentrated to China, followed by Indonesia, with the Latin American region coming in third. China, fostering one of the fastest-growing economies in the world and experiencing an unprecedented urbanization and motorization that has greatly transformed the nation's urban landscape over the last years, is the most fertile ground for new BRT schemes to prosper. Currently, 18 Chinese cities host at least one BRT corridor, but most of these schemes are of minor scale for the magnitude of the Chinese mega-cities. This trend is even clearer in India, where BRT operates in 8 different cities, serving only 390,000 passengers per day. 
TABLE 3. Complete List of Cities Hosting BRT Schemes

\begin{tabular}{|c|c|c|c|c|c|c|}
\hline Adelaide & Cannes & Evry & Joinville & Maubeuge & Port of Spain - Arima & Surat \\
\hline Ahmedabad & Cape Town & Fareham-Gosport & Jonkoping & Medellin & Porto Alegre & Swansea \\
\hline Almere & Caracas & Feira de Santana & Juiz de Fora & Merida & Prague & Sydney, Blacktown Rouse Hill \\
\hline Amsterdam & Castellon & Fortaleza & Kansas City & Metz & Prato & Sydney, Liverpool \\
\hline Auckland & Caxias do Sul & Gatineau & Kent & Mexico City & Puebla & Sydney Parramattarouse Hill \\
\hline Bangkok & Châlon-sur-saône & Goiania & Kesennuma-Tome & Miami & Pune & Taichung \\
\hline Barranquilla & Changde & Gothenburg & Kunming & Monterrey & Quito & Taipei \\
\hline Beijing & Changzhou & Guadalahajara & La Rochelle & Montevideo & Rajkot & Tehran \\
\hline Belém & Chiayi & Guadalupe & Lagos & Nagoya & Recife & Toulouse \\
\hline Belfort & Chicago & Guanzhou & Lahore & Nancy & Rio de Janeiro & Twente \\
\hline Belo Horizonte & Chihuaha & Guarulhos & Lanzhou & Nantes & Rosario & Uberlandia \\
\hline Bhopal & Chongqing & Guatemala & Las Vegas & Natal & Rouen & Urumqi \\
\hline Blumenau & Cleveland & Guayaquil & Leeds & Nazahualcoyoti & Runcorn & Utrecht \\
\hline Bogotá & Crawley & Haifa & Leon de los Aldama & New Delhi & Saint-Nazaire & Vancouver \\
\hline Boston & Criciuma & Halifax & Lianyugang & New York & Salvador & Waterloo \\
\hline Bradford & Curitiba & Hamburg & Liége & Nice & San Bernandino & Winnipeg \\
\hline Brampton & Dalian & Hangzhou & Lille & Niteroi & San Diego & Xiamen \\
\hline Brasilia & Diadema-Sao Paolo & Hefei & Lima & Oakland & Santiago & Yancheng \\
\hline Brescia & Douai & Indore & Lisbon & Oberhausen & Santos & Yinchuan \\
\hline Brisbane & Dublin & Ipswich & London & Olinda & Sao Paolo & York \\
\hline Bucaramanga & Ecatepec & Istanbul & Londrina & Orlando & Seoul & York Regional \\
\hline Buenos Aires & Edinburgh & Jaboatao dos Guararapes & Lorient & Ottawa & Snohomish County & Zaozhuang \\
\hline Caen & Eindhoven & Jaipur & Los Angeles & Panama & Sorocaba & Zhengzhou \\
\hline Cali & Enschede & Jakarta & Luton & Paris & Stockholm & Zurich \\
\hline Cambridge & Essen & Jinan & Lyon & Pereira & Stokton & \\
\hline Campinas & Eugene & Joao Pessoa & Maceió & Phoenix & Strasbourg & \\
\hline Campo Grande & Everett & Johannesburg & Maua - Diadema & Pittsburgh & Sumare & \\
\hline
\end{tabular}

Source: www.brtdata.org, December 2014 
Only three cities in Africa have introduced BRT: Johannesburg and Cape Town in South Africa and Lagos in Nigeria. In Oceania, there are six cities hosting a BRT scheme; five are in Australia. A seventh scheme in Melbourne (i.e., SmartBus) contains elements of BRT infrastructure but is no longer listed as such in the brtdata.org database. The introduction and usage of BRT in North America is limited compared to the potential opportunities that exist in the U.S. and Canada markets. Most schemes that are operating have small usage rates in relation to the dedicated BRT kilometers offered.

Europe, on the other hand, is a very different story when attempting to assess BRT's operability, productivity, and success. In Europe, the bus sector has a long tradition of innovation and development in introducing bus lanes, bus-only roads, traffic management measures to assist buses, and automatic dispatch and control systems - in some cases, as early as the 1970s (Hidalgo and Gutierrez 2013). Nevertheless, BRT has not been embraced with the same enthusiasm. One explanation is that during the 1990s, tramways were favored and received a lot of attention, while buses and bus systems were left behind. Nonetheless, the number of BRT systems in Europe is steadily increasing, especially in France and the UK.

Researchers and practitioners in Europe prefer to use the term Buses of High Level of Service (BHLS) rather than BRT (Finn et al. 2011). This is the case because they want to differentiate the European applications, which are based on improving passenger experience rather than simply focusing their efforts on how to supply high-capacity mass transit. In the report from CERTU (2005), BHLS is defined as "a public road transportation concept for the structuring services of the network that meet a set of efficiency and performance criteria, coherently integrating stations, vehicles, circulation lanes, line identifications, and operating plans in an on-going manner."

However, the BRT vs. BHLS theme is far from simply being a quantity vs. quality aspect. The advanced bus schemes across Europe, with the exception of Istanbul's Metrobüs, are not BRT systems that resemble Bogotá's TransMilenio or Curitiba's RIT but rather are BRTLite. BRT-Lite is a term that is more or less synonymous with BHLS, which explicitly refers to a system of buses with a high level of service that, despite its advanced characteristics, when compared with a conventional bus-line is not a fully developed BRT system, but rather a French/European BRT version of significantly smaller scale suiting European city needs. BHLS can have a considerable impact when implemented as part of the "co-modality" concept promoted by the EU-for example, working in cooperation between public transport fleet operations and parking management systems to promote BRT corridors (Deng and Nelson 2011).

\section{A Brief BRT History Lesson}

BRT is an evolution of bus priority measures, such as designated busways and bus lanes (Hidalgo and Gutierrez 2013) and reflects a vision that was inspired almost 80 years ago. The idea of using rubber-tired vehicles to provide rapid transit is well-documented in plans and studies that have been prepared since the 1930s, with growing emphasis on bus prioritization (Levinson et al. 2003). For example, in 1937, the so-called Chicago Plan called for converting three west-side rail transit lines to express bus operation on super highways 
with on-street distribution in central areas (Levinson et al. 2003). The term BRT was initially used in 1966 in a study for the American Automobile Association by Wilbur Smith and Associates, but a proper full-scale implementation came almost two decades later.

The first real BRT system was implemented in Curitiba in 1963, although dedicated bus lanes were not operating until 1974 (Rabinovitch and Leitman 1996). Curitiba, with 1.85 million inhabitants occupying a total area of $435 \mathrm{~km}^{2}$ (about 4,200 inhabitants per $\mathrm{km}^{2}$ ), is the seventh most populated city in Brazil and the largest in the southern region of the country. The city stands at the center of a metropolitan area that includes 26 municipalities with a total population of 3.17 million inhabitants. As early as the 1960s, Curitiba's policymakers had the inspiration to direct the city's growth by integrating urban transportation, land-use development, and environmental preservation using bus-based transit innovation as their main apparatus.

In a December 2013 discussion with the authors, the Mayor of Curitiba, Jaime Lerner, the political champion who introduced this first BRT application in the world, stated that "the inspiration behind the creation of a metro-nized, in terms of performance bus system," was based on three parameters: 1) reflecting the restrictions of the local economy that could not cater to the massive financial needs for building and eventually sustaining a metro system; 2) understanding that the future of transportation was on the surface (and not underground) - he explicitly referred to "the need to have an interactive urban environment that integrates mobility, in a very visible way, with the overall sustainability focus of the city"; and 3) maximizing the potential of an already-existing bus system by transforming it in a cost-effective but yet unparalleled way that could fit his vision of a city working, living, and moving as a whole like a living organism.

As originally described by Lindau et al. (2010), the Curitiba bus system evolved from conventional buses in mixed traffic to busways, which were later fitted with floor-level boarding, prepayment, and articulated buses, creating the first full BRT system in the world. Later, the city introduced high-capacity bi-articulated buses and electronic fare ticketing systems. In 2007, RIT (the name of the scheme) had 2.26 million trips per working day transported by a fleet of 2,200 buses that produced 483,000 km per day. In 2009, the RIT was upgraded with the introduction of the Green Line, its sixth BRT corridor, which includes the operation of 100 percent bio-diesel articulated buses. As of 2010, some of Curitiba's corridors had achieved performance to levels that are typical for metro systems (Lindau et al. 2010). The capacity of the Boqueirão Corridor, for example, serves up to 89,000 passengers per day, and its operating commercial speed for the express service is approximately $28 \mathrm{~km} / \mathrm{h}$. Today, RIT is responsible for 508,000 passenger trips per day over its $81 \mathrm{~km}$ (www.brtdata.org, December 2014).

Curitiba's operational framework was adapted to a significant degree for introducing BRT corridors in places such as Quito (1995), Bogotá (2000), Los Angeles (2000), Mexico City (2003), Jakarta (2004), Beijing (2005), Istanbul (2008), and Guangzhou (2010), to name a few. Nonetheless, sufficient time passed for this public transit philosophy to disseminate to other locations. The vast majority of cities around the world that adopted BRT operations embraced this choice from 2000 onward, as illustrated in Figure 2. 


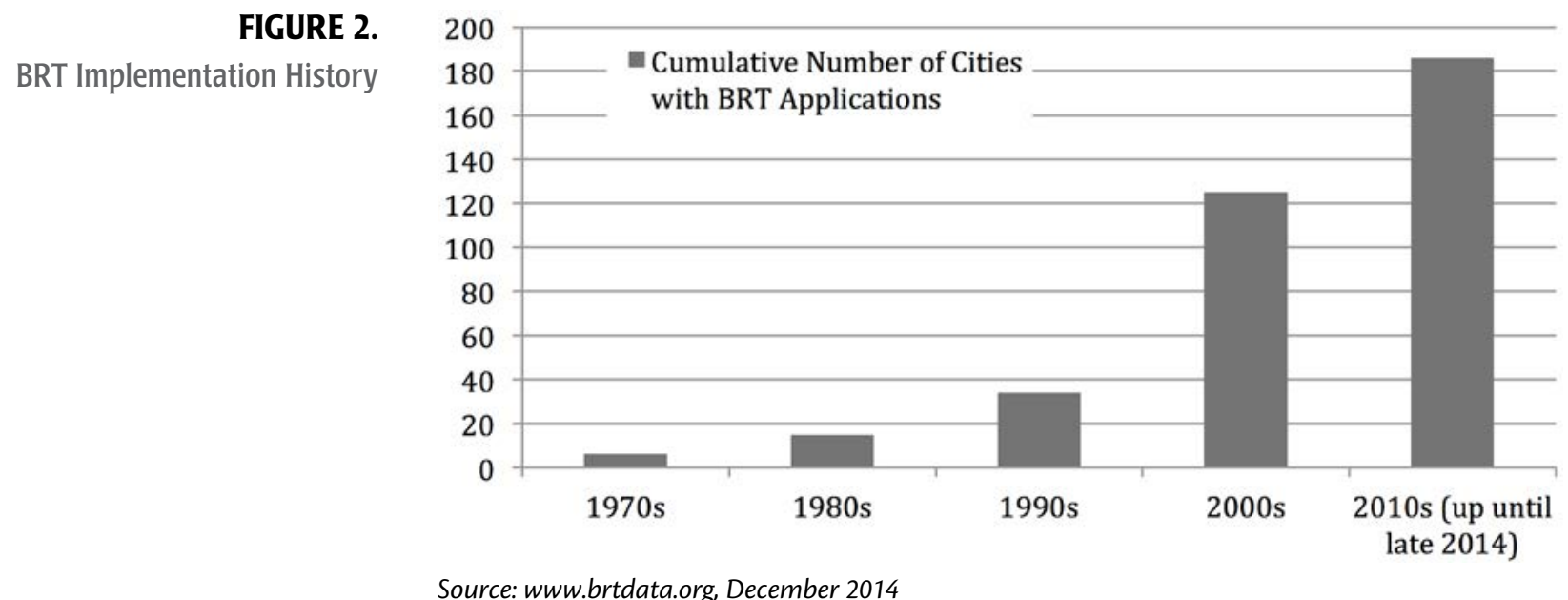

\section{Presenting and Discussing Local BRT Applications}

The main focus of this section is to present updated information on specific local BRT applications that could be representative of their geographical region, followed by appropriate discussions. These discussions could be generalized into wider context for cities with similar characteristics and could serve as valuable lessons for building future BRT applications. There are many more examples that could have been discussed, but due to space restrictions, this was not an attainable choice.

\section{South America}

\section{TransMilenio, Bogotá, Colombia}

Other than Curitiba, the influence of Bogotá has been particularly important in setting the standards for what BRT is really about. The TransMilenio BRT system is the most powerful BRT reference for planners and practitioners worldwide (Gutierrez 2010). Bogotá is the capital and largest city of Colombia, with 7,760,500 inhabitants. It is among the 30 largest cities in the world and has 20 localities, or districts, that form an extensive network of neighborhoods. TransMilenio, widely known as the "Jewel of Bogotá," has received many tributes, including the Stockholm Partnership Prize in 2002. It is the largest investment in public transportation in Colombia in the last decade, with significant impacts on travel times, transportation costs, the environment, accidents, and urban development of the nation's capital (Hidalgo et al. 2013). It was built in three years, effectively from scratch, as the answer to the persistent demand for a metro system (Gilbert 2008). On an average working day in 2014, the system carried 2.21 million passengers in $113 \mathrm{~km}$ of lanes in 11 corridors (www.brtdata.org, December 2014).

TransMilenio began operations in December 2000. Its key features as described by Gilbert (2008) include the following:

- The system was built in stages, aiming to cover 80 percent of the urban transport needs of the city (Gómez 2004).

- Each corridor is built along the city's major roads, and the construction of the bus stations, garages, bridges and other infrastructure was financed by public funds. 
- TransMilenio operates using a public-private partnership mechanism. City administration is responsible for the construction and maintenance of the infrastructure (through the Urban Development Institute) and for the planning, management, and control of the service (through Transmilenio S.A., the private operator). The system operated originally on a commission of 3 percent of the fares collected, a percentage that has risen over time (Hidalgo et al. 2013).

- There is no operating subsidy.

- Red articulated buses operate along reserved corridors, with two exclusive lanes each way on most routes; a feeder system takes passengers to the main stations.

- In 2011, 1,262 articulated buses and 10 bi-articulated buses were operating 114 stations around the city, in addition to 519 conventional $12 \mathrm{~m}$ buses that operated within the 83 different feeder routes (Hidalgo et al. 2013).

- Each articulated bus can carry 160 passengers, with 112 standing and the remainder sitting.

- The red buses belong to 7 "modern," private companies that have contracts with the city; the green feeder buses belong to another 11 companies.

- Some buses stop at every station; others are express services.

- Passengers board and alight the buses at special stations, many of which can be reached by pedestrian bridges to avoid accidents and to speed up loading.

- Passengers purchase travel cards before boarding. A fixed fare is charged whatever the length of the journey. The use of the feeder bus system is free; passengers are charged only when they board on the articulated buses. The payment system also embraces the use of a smart card (Hidalgo et al. 2013). The fares are collected by Transmilenio S.A.

- Transmilenio S.A. monitors and controls the system through a GPS system and communicates with the drivers through a wireless telecommunications system.

- User information is achieved through a fixed signage and dynamic display panels (Hidalgo et al. 2013).

- The buses have to be replaced on a regular basis, approximately every 10 years, although this can be extended to 15 years if the buses have not completed an agreed mileage.

- The drivers are salaried employees of the bus companies.

TransMilenio may be a minor miracle, but Bogotá is still in need of improving its transport system. Perhaps the main lesson that other cities planning to invest in busways should learn is that TransMilenio-type systems can work efficiently and should be encouraged, but unless parallel changes are made to the rest of the transport sector, real progress will be slowed and, in a worst-case scenario, vested interests may actually undermine the viability of a new BRT system (Gilbert 2008). 


\section{MIO, Santiago de Cali, Colombia}

Santiago de Cali (or Cali), the third largest city in Colombia, with a population nearly 2.5 million residents, is among the most recent South American cities to adopt a BRT system and is in the process of replacing its traditional bus public transit system with an integrated mass transit system. This city-wide transportation project is central to a larger urban revitalization plan intended to encourage economic growth and to alter the image of both the city and the country to residents and outsiders. What defines this scheme is the intention of planners to create a system that prioritizes equity over other potential goals. As Delmelle and Casa (2012) report, the policymakers' ambitions focus on developing a scheme that promotes equitable access to all residents and access to a large number of urban opportunities. This is a scheme that on a daily basis accommodates 530,000 passenger trips in its 6 corridors that extend to $39 \mathrm{~km}$ (www.brtdata.org, December 2014).

\section{Lessons to be Learned by South American Applications}

Since BRT has a long tradition in South America, a discussion about South American scheme variety and success (or failure) as a whole is a meaningful process. This discussion, nonetheless, could be generalized into a wider context since these findings could be applicable to other systems that have not yet achieved the levels of maturity of the South American schemes.

After Curitiba opened the first BRT system, other cities in Brazil introduced systems with some of the same characteristics but with much lower speeds, capacities, and customer comforts. These light BRT systems-São Paulo's passa rápido corridors, for examplebrought some real benefits to passengers but were far less appreciated by the general public. As a result, Brazil lags behind Colombia in terms of leading BRT development (Weinstock et al. 2011).

BRT systems in South America (and in Asia, in this case, since there are similarities) feature a diversity of scope and level of integration. There are single-corridor projects that do not integrate with feeder services and other transport modes (e.g., Mexico City, Beijing), projects with sequential implementation of non-integrated corridors (Quito, Jakarta), schemes that gradually implement physically-integrated corridors (Bogotá, Guayaquil), and others that deploy extended route re-organizations (São Paulo, Santiago, León) (see Carrigan et al. 2011). A strong political champion has proven to be an asset in the development and implementation of BRT (Lerner 2013).

The fares for South American BRT projects with competitive bidding for bus operating concessions (e.g., Bogotá's TransMilenio, Pereira's Megabus and TranSantiago) often have been determined through the bidding process itself. Initial user fares were calculated based on prospective operator bids, and the contracts then issued for operating have included adjustment formulas for future rises in labor and fuel costs over time. In other systems, political authorities defined fares that did not reflect the actual costs of the system or the required levels of subsidy. This approach can have adverse effects. For instance, Quito's system was unable to generate enough funds to pay the operators of the Ecovía buses, and the BRT systems of Mexico City (and, similarly, Jakarta and Beijing) were financially challenged until fare increases were approved. Setting fares related to knowledge of the costs and an understanding of subsidy requirements are necessary to ensure financial 
sustainability for operators and funding authorities as well as continued political buy-in (Carrigan et al. 2011).

It is also common for cities to incorporate existing operators into the new BRT system to minimize political and contractual risks referring to service operation. Cities in South America (and now in Asia and Africa as well) have encouraged small transport businesses and operators to organize themselves into formal companies through restricted bidding for operation contracts or through direct negotiations (Carrigan et al. 2011). This encourages local communities and businesses to engage more actively with the scheme of their city by sharing some responsibility for its functional operation. Even more important, however, this helps to secure working posts that could be in doubt if a large contractor was in command-something that influences local economic development positively. This is an operational issue that perhaps deserves a study on its own, but since it is an important success ingredient for BRT, it is reported as such for the sake of a more holistic approach.

\section{Europe}

\section{Metrobüs, Istanbul, Turkey}

A scheme that is considered among the most successful is Turkey's Metrobüs, the only intercontinental BRT system in the world. This is a success story not related with South American schemes, although it was inspired by them. The implementation of Metrobüs started in 2007. It was initially built on the European side of Istanbul through a high-demand arterial and received criticism for being preferred over rail alternatives. The section that was built in 2009 runs over one of the two Istanbul Strait (Bosporus Strait) bridges connecting Asia and Europe, by which Metrobüs has uniquely acquired the distinction of crossing a major water barrier and connecting two continents. Istanbul Strait is a major transportation bottleneck and source of congestion, and Metrobüs is the only transit system for crossings.

Shortly after the opening of the bridge section, the whole system recorded a directional capacity of 24,000 passengers per hour and patronage of 620,000 daily trips (Alpkokin and Ergun 2012). The one-corridor BRT scheme after its fourth phase in 2012 extends to $51.3 \mathrm{~km}$ (Yazici et al. 2013). Currently, Metrobüs carries 750,000 passengers per day serving Istanbul, one of the largest cities in the world, with a population of more than 13 million inhabitants (www.brtdata.org, December 2014), which, similar to other megacities in terms of size and complexity, has a metropolitan area even larger. Metrobüs uses the application of a median busway with center island stations that was built within the median of the freeway D100 by removing a travel lane in each direction. Bus operation is counter-flow to reduce costs and implementation times and uses conventional buses with right-hand doors. The entire Metrobüs system has a dedicated right-of-way in Istanbul, with the exception of mixed traffic operations on the Bosporus Bridge.

Alpkokin and Ergun (2012) conclude their assessment of Metrobüs by reporting that "all the information of improved ridership and capacity proves that Istanbul Metrobüs achieves one of the highest patronage levels amongst similar BRT systems, which provides evidence to support the effective operation of BRT systems." 


\section{Stombussar, Gothenburg, Sweden}

Gothenburg has approximately 540,000 inhabitants and is divided by the Gothia River, with the south and the north parts crossed by two bridges and one tunnel. Public transport accounts for 29 percent of all trips; 48 percent are by private car, 14 percent by motorcycles and non-motorized vehicles such as bicycles, and 9 percent by walking. The public transport system in Gothenburg consists of trams, BRT-Lite routes, and other bus services including express buses. There is also a ferry service across the river and to/ from the archipelago. Most public transport journeys are made by trams (60\%), but the BRT system is gaining in popularity and carries around 15 percent of the passengers of all public transport trips (Trafikverket 2014), that equal approximately 25,000 passenger trips per day (www.brtdata.org, December 2014).

The BRT system, or, more precisely, the trunk bus system, was first introduced in 2003. Currently, eight lines are considered trunk bus lines or "stombusslinjer." Line 16 initially had a 10-minute frequency during peak hours; the current frequency is 5 minutes during most of the day and 2.5 minutes in the most demanding directions during peak hours. The other seven BRT routes run with at least 10-minute frequencies during daytime, in some cases reinforcing traffic during peak hours. To minimize the times at each bus stop, travelers are allowed to get on and off through all doors, a so-called "open visa" regime. This corresponds to the principles that apply to trams in Gothenburg, but is not allowed in other, ordinary bus lines.

Buses are given priority at all traffic lights en route. The position of all bus stops was reviewed, leading to a minimum number of bus stops in relation to traveler needs, and special bus lanes and bus streets were created. When planning the routes, efforts were made to avoid sharp curves and lateral movements; this has been achieved by providing a straight line into and out of the bus stops and bus lanes, which run straight through roundabouts, etc. All these actions lead to a higher average speed. Most bus stops in the BRT system are equipped with real-time information displays, presenting information on next departure as well as disturbances and delays. On all buses, internal displays inform the passenger about the next two stops. A special road map presents the trunk bus lines together with the tram system to further stress the relationship between the two. The ticketing system is an electronic smart card system. Tickets cannot be purchased on board, but individual tickets can be purchased via SMS just before the trip and are valid for 90 minutes, or cards can be purchased from local shops. Approximately 65 percent of passengers use monthly passes.

The entire bus fleet consists of low-floor buses with wheelchair ramps. In addition, all stops have a raised platform to improve accessibility for mobility-challenged passengers. The buses have a unique and uniform design to make them easily detectable in city traffic. For interior design, care was taken in the choice of colors, materials, and lighting to make the travel experience more pleasant for travelers and to assist passengers with disabilities.

It should be noted that this BRT scheme is substantially scaled down compared to the world's leading BRT schemes; it is not oriented towards dealing with higher capacities but, rather, emphasizes the provision of high-quality services. Conclusions from previous Swedish research on BRT indicate that there is no place for full-scale BRT schemes in 
Sweden, even though Swedish towns and cities could benefit from the image, flexibility, speed, and quality that BRT symbolizes (Stojanovski 2013). The urban form, the road hierarchies, and the dispersed and fragmented urban structure of Swedish towns and cities and low densities were identified as main obstacles (Kottenhoff 2010).

\section{Asia}

\section{TransJakarta, Jakarta, Indonesia}

Jakarta is the capital and largest city of Indonesia and is located on the northwest coast of the island of Java. It is the country's economic, cultural, and political center and, with a population of around 10 million, is the 13th most populated city in the world. Transjakarta BRT System launched its first corridor on January 2004 on a trial basis, beginning revenue operation on February 2004 (Ernst 2005). This was the first fully operational BRT system in Asia. During its first year, it served 15.9 million passengers. Beginning with just 12.9 kilometers, Trans)akarta is now 206 km (www.brtdata.org, December 2014), larger than the BRT systems in Curitiba and Bogotá (Yunita 2008).

This is a scheme that has all the key elements of a BRT system. It is founded on a designated busway that is physically separated from mixed traffic, except for very few cases where segregation was not feasible. Transjakarta offers facilities such as air-conditioning and pre-paid boarding that distinguish it from other buses. Currently, 12 corridors operate, serving 370,000 passenger trips per day (www.brtdata.org, December 2014). In its first year of operation, Transjakarta was responsible for a significant modal shift, with 14 percent of private car users using BRT (Susilo et al. 2007), a measurement that reflects the period occurring four months after the launching date of the first eight corridors.

TransJakarta's ridership is rather low, with systems that have less than one-quarter of TransJakarta's infrastructure carrying more passengers per day. For example, Belo Horizonte's BRT system is approximately 5 times smaller than Transjakarta, with 5 fewer corridors and carrying 682,000 passengers per day on its articulated buses. One effort to improve the customer experience and attract ridership included the installation of water fountains in several stations, intended for passengers observing Ramadan, the Islamic month of fasting, to be able to break their fast in the station during their commute home. The cost of the water purifiers was about $\$ 2,136$ each (Yunita 2008).

The main problems of the scheme are long queuing times and insufficient bus frequency. The initial corridors were constructed for buses with only one door, constraining the number of people who could get off or on the bus at one time. The new corridors will include a fix to this problem. Information provision is not efficient since it is provided only in stations by ticketing officers, security officers, and a display board. Cleanliness and maintenance are important concerns as well.

\section{BRT1, Beijing, China}

Beijing is the capital of China and one of the most populous cities in the world, with more than 20 million inhabitants. The metropolis is governed as a direct-controlled municipality under the national government, with 14 urban and suburban districts and 2 rural counties. Beijing Southern Axis BRT Line 1 (BRT1) is the first BRT system implemented in China and the first large-capacity rapid bus line based on the needs of developing public 
transportation, which was designed using foreign advanced ideas and technology as reference (Lin and Wu 2007). BRT1 started commercial operations in December 2004 with a pilot line of only $5.5 \mathrm{~km}$ in length. In December 2005, BRT1 began full operations and was extended to $15.8 \mathrm{~km}$. It should be noted that from proposal to trial operation, the time span of implementing BRT1 was relatively short. Most lanes are physically segregated in the median of the road, except for $2 \mathrm{~km}$ from Qian'men to Tian'an'men. Six of the 17 stations of the corridor are transfer stations (Deng and Nelson 2013). Accessibility to the city center has been significantly improved for residents along the BRT corridor.

The BRT system investment at Beijing Southern Axis Corridor included significant expenses for the creation of the necessary road-reconstruction project, stations, and intelligent transportation systems (ITS). The investment in the road reconstruction project was about 321.31 million yuan, and the investment for the stations and ITS (including operation for stations, parking lots, vehicles, etc.) was approximately 288.19 million yuan, for a total cost of 609.5 million yuan; construction cost per kilometer was about 38.1 million yuan (Lin and Wu 2007), a cost in American dollars (in 2014 values) of approximately $\$ 6.2$ million.

In Beijing, the local authority has faced increasing difficulties in paying off debts for subsidizing its metro and light rail operations and for expanding the rail network to increase coverage. In a pre-implementation cost-benefit study on three transport improvement alternatives (busway, street-level light rail, and elevated rail) in a congested corridor in Beijing, it was found that only the busway showed a positive net present value (Deng and Nelson 2013). This rationale led Beijing policymakers to implement, on a relatively small scale (for the city standards), BRT to save costs and eventually provide high-quality services within a short implementation time.

Currently, Beijing has 4 corridors covering $74 \mathrm{~km}$ of routes and hosts on a daily basis 305,000 passenger trips (www.brtdata.org, December 2014). The lines use vehicles with a passenger capacity of 180 persons (Lin and Wu 2007), and all are low-floor buses and cost about US\$250,000 each, including features such as automatic stop announcements, three double left-side doors, and air conditioning (FTA, 2006). The buses are mounted with GPS terminal equipment and meet universal emission standards. The speed of the buses reaches $26 \mathrm{~km} / \mathrm{h}$, and (according to Lin and Wu 2007) the overall travel speed of general traffic after BRT implementation of the Southern Axis Line has increased by $2.26 \mathrm{~km} / \mathrm{h}$.

A user survey conducted by Deng and Nelson (2012) suggested that passengers were generally content with the BRT service provided in the Beijing Southern Axis BRT Line 1, with 85.5 percent rating overall satisfaction as "very satisfied" or "satisfied." High speed and convenience were the main factors encouraging passengers to use BRT. It was also found that passengers who had a car alternative were more likely to give lower satisfaction ratings regarding the reliability, comfort, cleanliness, and overall satisfaction of the BRT service.

Overall, the implementation of BRT in Beijing is regarded as a considerable success because of its prominent flexibility, transit speed (close to that of the Beijing Metro), and user satisfaction (Deng and Nelson 2012, 2013; Lin and Wu 2007). However, some problems do exist. In Beijing, an impressive feature of BRT stations is a pedestrian overpass or 
underpass, which provides safe pedestrian access; adding lifts and elevators would make these stations even more accessible to mobility-challenged groups. Fares are below the operation cost level, which has generated considerable financial difficulties for the operators. Currently, Beijing's BRT is heavily subsidized by the local government, but because it has high passenger volume levels and low labor costs, it could be profitable, provided that the system operation structure is redesigned accordingly. The local authority needs to re-examine the effect of subsidies on operational efficiency and conduct a full review of its fare policy and structure to improve the operational sustainability of BRT. Adding more express buses at large stations and intersection services during peak-hours while reinforcing the fleet with super-capacity vehicles could, according to Lin and Wu (2007), bring immediate improvements to the system.

\section{Unrealized Potential for BRT Investments in Asia}

In many developing Asian cities, the growth of transportation needs is very rapid and uncontrolled, causing various impacts on the environment and human welfare (Satiennam et al. 2006). The reality is that until recently, heavy investments have been made exclusively in building metro and light rail systems as a means to meet massive travel demand. Pucher et al. (2007) suggest that although metro and light rail projects have gained extensive political support in Asia, in some cases, this is mainly because "rail symbolizes modern, advanced technology and offers politicians tangible, highly visible achievements to impress their constituencies and the rest of the world." Thus, the prioritization of rail-based solutions was primarily founded for image and national pride purposes and not on the provision of a mechanism adequate to deal with urgent traffic congestion problems.

BRT has recently emerged as an attractive urban transit alternative in many Asian cities due to its financial sustainable, ecologically-friendly character and its flexible implementation. However, it seems to be difficult to introduce BRT, at least on a scale that reflects the size and traffic challenges of Asian mega-cities. Ten countries and 38 cities in Asia have a BRT scheme to date, but none is comparable in size or performance to the schemes of South America. Some of them also lack innovation and are limited to unsuccessfully adapting BRT operations that do not fit the local needs of the city hosting them. For instance, after Indonesia opened Transjakarta, a system with significant problems of its own, other cities across Indonesia began opening copycat systems, the best of which brought about only marginal improvements and the worst of which made conditions worse. Chinese and Indian cities, after gaining some limited familiarity with Bogotás TransMilenio, also made a number of sub-optimal bus system improvements that were branded as BRT but which could not be judged as cost-effective (Weinstock et al. 2011).

Furthermore, the lack of upfront integration of road design, public transportation planning, land-use planning, and early-stage public consultation has created challenges to providing high-quality public transport services on many new urban corridors (Jiang et al. 2012). Deng and Nelson (2010) add that, despite the fact that BRT systems are successfully in operation across the world (and in Asia in particular), the image of BRT is not yet well understood by most decisionmakers. This means that it is difficult for them to transform a concept that is often misunderstood into new local applications that could genuinely 
improve road traffic conditions. Yet, with more than 100 cities of more than 1 million in population only in China, the urban transportation market in Asia is very large (FTA 2006) - too large to address by simply supporting car-orientated operations and conventional public transport services.

\section{North America}

\section{HealthLine, Cleveland, USA}

The most successful example of BRT in the U.S. (with a BRT Standard score of 63/100 compared to Eugene's EmX 61, Los Angeles' MetroRapid 61, Pittsburgh's Martin Luther King, Jr. East Busway 57, and Las Vegas' MAX 50) is the $11.4 \mathrm{~km}$ Euclid Corridor Transportation Project, also known as HealthLine. This is a scheme that is not really comparable to the productivity, efficiency, or size of a scheme such as Bogotás, whose BRT Standard score is 93 . Healthline is a one-corridor scheme serving 15,000 passenger trips per day (www. brtdata.org, December 2014).

This project was created in response to the need for providing an efficient public transit service connecting the city's main employment centers. The Greater Cleveland Regional Transit Authority (RTA), the Northeast Ohio Areawide Coordinating Agency (NOACA), and the City of Cleveland had studied transit options in Cleveland for four decades, culminating with the consensus in 1995 that BRT would be the most cost-effective option to provide high-capacity transit service for the city (Weinstock et al. 2011). The project details for the Euclid Corridor Transportation Project were finalized in 1999 following a series of 12 public consultation meetings.

Before the system opened, average bus speeds in the corridor were only $15 \mathrm{~km} / \mathrm{h}$. Line 6 on the Euclid Avenue corridor was one of the most heavily-used routes in the city, accounting for 10 percent of the total passenger trips. Euclid Avenue also had lines 7 and 9 operating on part of the corridor. The operational plan for the HealthLine converted line 6 into an upgraded service with new articulated BRT buses that operate mostly within a newly-constructed segregated right-of-way. The original low-floor 7 and 9 buses also are able to use the BRT infrastructure at station stops with right-side boarding. A total of 32 buses also use the BRT corridor in some places. Together, these 4 lines average an interval of 2.1 minutes between buses during the peak, and speeds in the corridor average a respectable $20.11 \mathrm{~km} / \mathrm{h}$ (Curitiba BRT averages about $21.06 \mathrm{~km} / \mathrm{h}$ and Bogotá averages $26.2 \mathrm{~km} / \mathrm{h}$ ). More than 13 additional routes that overlapped the corridor for short distances or were in the impact area of the corridor have been rerouted. Some of the speed increase resulted from the elimination of stops, which some residents complained about along with the inconvenience resulting from the changes in routes, but that was the only negative side-effect.

Daily ridership increased by 60 percent after 2 years of operation. The project's total budget was approximately $\$ 200$ million, but only $\$ 50$ million was allocated for buses and stations; the remainder was directed towards other corridor improvements such as roadways, utilities, new sidewalks, and street furniture. The cost of the busway itself, therefore, was only about $\$ 7$ million per mile, including rolling stock. The investment has resulted in nearly $\$ 4.3$ billion in economic development for the area (Zingale and Riemann, 2013) in 
real estate investments along Euclid Avenue, one of the city's most historically-significant corridors.

A very intriguing factor of the scheme (that perhaps could be a point of reference for more BRT schemes) relates to the fact that Greater Cleveland sold the naming rights of the line to help fund the system. The Cleveland Clinic and University Hospital jointly purchased the naming rights, resulting in the HealthLine name. This partnership will provide the system with $\$ 6.75$ million in additional funding, dedicated to maintenance, over the next 25 years.

\section{North America is Still "Testing" BRT}

The development of BRT systems is relatively recent in the United States; however, several systems are operating, and many more are being planned (Perk et al. 2010). Until recently, the U.S. and Canada (partly because BRT is not ideal for the population density of the typical Canadian urban structure) have not yet relied heavily on BRT. Having witnessed the success of BRT schemes such as those in Curitiba and Bogotá, a number of American cities began developing BRT-type systems. Some of these systems have brought significant benefits and won public approval. However, even the best U.S. systems lack some key characteristics of the world's best BRT systems, and none have fully captured the imagination of American motorists and voters (Weinstock et al. 2011).

American cities started investing in BRT as a viable alternative after it was solidified as a worldwide phenomenon. However, the concept of employing rubber-tired vehicle fleets to provide rapid transit and the term BRT itself could be of American origin (Levinson et al. 2003). Since there is still no consensus on what constitutes a full-scale BRT system (Wirasinghe et al. 2013), the not particularly infrastructure-heavy American BRT systems have been labeled by some (e.g., Weinstock et al. 2011) as "modest bus system enhancements corrupting the BRT brand."

Nonetheless, each BRT system is a unique solution fitting the needs of the city in which it is implemented and should be addressed as such. The role BRT is asked to play in the U.S. because of federal and other cultural and institutional differences is that of a complement and not of a sole solution. Similar to Europe, there is a focus on quality rather than quantity. Perhaps, to allow for BRT to grow to its full potential in North America, more comprehensive understanding is needed of the relationship between land use and BRT, particularly in comparison with other fixed-guideway modes (Perk et al. 2010). Understanding the mode's impacts on property values, in particular, could be another key for embracing the measure if the impact is somewhat comparable to that of rail-based services (Perk et al. 2013). The emergence of BRT, in this sense, should not be seen as a problem despite all its current limitations, but rather as "a unique opportunity to change negative perceptions regarding public transit in North America," as Hess and Bitterman (2008) argue.

Currently, 18 cities in the U.S. host 32 corridors and $548 \mathrm{~km}$ of dedicated BRT road infrastructure, but only 365,000 passenger trips per day (www.brtdata.org, December 2014) take place, which, in comparison, is less than half of those completed daily in Instabul's Metrobüs. Canada, in respect, has 8 cities with BRT schemes, hosting 530,000 passenger trips in 18 corridors spanning $250 \mathrm{~km}$ (www.brtdata.org, December 2014). 


\section{Africa}

\section{Lagos BRT-Lite, Lagos, Nigeria}

Among the three African BRT applications, the most recognizable is perhaps the one in Lagos, Nigeria. Lagos is one of the fastest growing cities in Africa. Data for "building up" urban area population is a particular concern in Nigeria; the 2006 census results were highly disputed. For example, the federal census indicated a population for the state of Lagos of 9.1 million; a parallel census conducted by the state found the population to be 17.5 million (Demographia 2014).

The $22 \mathrm{~km}$ Lagos route is Africa's first BRT scheme and became operational in March 2008. It is termed "BRT-Lite," meaning that it is not a scheme of the highest specification such as TransMilenio in Bogotá. It is a new form of BRT, focused upon delivering a system to meet key local user needs, with the aim of improving quality of life, economic efficiency, and safety within a clearly-defined budget. The implementation of a 15 -month conception-to-operation program, together with its delivery at a cost of $\$ 1.7$ million per $\mathrm{km}$, makes its development unique internationally (Brader 2009).

The Lagos BRT-Lite carries almost 200,000 people per day (www.brtdata.org, December 2014). Its single route is 65 percent physically-segregated and 20 percent separated by road markings. However, its success is not purely based on its infrastructure but on a holistic approach that involved the reorganization of the city's bus industry, financing new bus purchases, and creating a new institutional structure and regulatory framework to support it, together with the training of personnel to drive, maintain, enforce, and manage BRT (Brader 2009). An early evaluation of the scheme showed that users were saving journey time, had fewer interchanges en route, were traveling cheaper, and felt safer (Brader 2009). Adebambo (2009) also suggests that BRT has a significant impact on passenger satisfaction in Lagos metropolis; it has helped to improve the quality of life of not only its users but also those that travel along the corridor using other modes, as well as those who choose to locate their businesses there. Businesses within the corridor saw the scheme as a positive addition, improving accessibility and aiding their access to staff and the ability of their staff to travel for work-related duties (Brader 2009).

Negative aspects relate primarily to the need for more buses and more routes. Problems exist, and improvements relating to the system's efficiency are necessary. According to Adebambo (2009), there is a need, for instance, to ensure greater coordination with local planning and operating agencies for the purpose of identifying BRT potential, and a need to conduct research, develop operational techniques, and promote the use of ITS technology to enable safe and efficient deployment of BRT. BRT implementation also may require policy and institutional reforms, such as changes in transportation planning and roadway management practices (to give buses priority in traffic), vehicle purchasing, transit regulations and contacting (to maintain a high quality of service), and urban design (to increase development near BRT routes). The scheme overall seems to have a beneficial effect upon the quality of life of the commuting population of Lagos. 


\section{Oceania}

\section{Brisbane Busway, Brisbane, Australia}

Australia and New Zealand, due to their small populations compared to their vast landmasses, are more likely than most countries to have strict limits on public spending, including transport infrastructure and operations. This means that bus-based systems can be the only viable solutions for some Oceanic cities. Australian BRT systems have been noted as being particularly diverse in design (Currie 2006), with systems now operating in Sydney, Brisbane, Adelaide, and, to a lesser extent, Melbourne (Currie and Delbosc 2011). The system in New Zealand is the one-corridor Northern Busway in Auckland, operating $22 \mathrm{~km}$ and generating 22,900 passenger trips per day (www.brtdata.org, December 2014). The Adelaide O-Bahn is the oldest BRT system in Australia and one of the first BRT systems worldwide; it opened in 1989 (Currie 2006).

The Brisbane Busway is the largest BRT system in Oceania, with 3 corridors running on $28 \mathrm{~km}$ and serving 356,800 passenger trips per day (www.brtdata.org, December 2014), which is about the same passenger volume as the huge TransJakarta scheme that was built to cater the needs of a city five times the size of Brisbane. The system is recognized as one of the most successful BRT systems in a developed economy, and, by Australian standards, is regarded as one of the most successful mass transit systems, delivering fast, comfortable, and cost-effective urban mobility through the provision of segregated rightof-way infrastructure, rapid and frequent operations, and excellence in marketing and customer service (Gollota and Hensher 2008). For the high-level strategic criteria of value for money and increased accessibility, connectivity, and visibility, the Brisbane BRT excels, according to Gollota and Hensher (2008).

\section{Conclusions}

BRT systems are celebrated worldwide as an increasingly popular public transport development option (Currie and Delbosc 2011). This is due to their promise for delivering relatively low-cost, rapidly-implemented, flexible, and high service quality solutions to developing cities' transportation needs (Wright and Hook 2007). There is an increasing number of highly-congested urban environments in need of a public transport mode with a vast potential for eco-innovation that could be assessing the merits of BRT. As pointed out herein, if BRT is well-designed and supported adequately by local policymakers, it can be a high-capacity public mode that could capture road-user loyalty. Furthermore, by reviewing BRT examples from all over the world, and especially concentrating on cases that have been revolutionary, this work provides an identification of prototype mechanisms for reconstructing success.

Combining the quality standards of a tram or metro system with the flexibility and ease of a conventional bus system at a significantly lower expense than that related to fixed rail operations could challenge the merits of car-oriented mobility in any eco-friendly society. International practice supported by current BRT user satisfaction levels (as reported, for example, for Beijing by Deng and Nelson 2012) suggest that BRT schemes could be highly-acceptable strategies for relieving traffic problems and promoting sustainable living conditions. 
BRT is a very demanding public transit medium that could transform the whole transport system within a city with two distinctive approaches-by re-allocating road space and by reforming the priorities of the city's urban development policy. In addition to BRT's dedicated road space requirements that call for the introduction of bus lanes on existing streets and bus streets completely separated from traffic, BRT is based on a wide variety of other rights-of-way, including bus priority in signalized intersections. These could radically affect the current balance of traffic prioritization, minimizing the dominance of automobiles in streets. Thus, introducing a full-scale local BRT scheme could rearrange the entire dynamics of a city's mobility and, ultimately, force dramatic changes in modal share.

Nonetheless, if the system fails to be attractive to the commuting audience, it could end up as an expensive fiasco. In such a case, the scheme could, instead of promoting alternative and greener mass transportation, worsen the inner-city road conditions in terms of traffic congestion by depriving road space from other more successful transport modes. Therefore, strong political consensus, branding, image-making, marketing promotion, and the provision of user education are of invaluable importance for 1 ) easing the transition from conventional bus services to BRT and 2) solidifying BRT as a tangible long-term solution that could provide vital societal services for all road users and eventually become iconic for the very identity of the city hosting it.

\section{References}

Abelson, P. W. 1995. Cost benefit analysis of proposed major rail development in Lagos, Nigeria. Transport Reviews 15(3): 265-289.

Adebambo, S. 2009. Impact of bus rapid transit on passengers' satisfaction in Lagos metropolis, Nigeria. International Journal of Creativity and Technical Development 1(1-3): 106-122.

Alpkokin, P., and M. Ergun. 2012. Istanbul Metrobus: First intercontinental bus rapid transit. Journal of Transport Geography 24: 58-66.

Badami, M. G., and M. Haider. 2007. An analysis of public bus transit performance in Indian cities. Transportation Research Part A 41(10): 961-981.

Brader, C. 2009. Lagos BRT-Lite: Africa's first bus rapid transit scheme. Lagos BRT-Lite Summary Evaluation Report, Integrated Transport Planning Ltd. and IBIS Transport Consultants Ltd. for LAMATA.

BRTdata.org. 2014. Global BRT database. Available at www.brtdata.org (last accessed December 10, 2014).

Canadian Urban Transit Association (CUTA). 2004. Bus rapid transit: A Canadian perspective. Research Report: McCormick Rankin Corporation for CUTA, Toronto.

Carrigan, A., D. A. Hensher, D. Hidalgo, C. Mulley, and J. Muñoz). 2011. VREF Book Chapter 10: The complexity of BRT development and implementation. Bus rapid transit: Across latitudes and cultures. 
CERTU 2005. Bus with a high level of service: Concept and recommendations. Centre for Studies on Urban Planning, Transportation, and Public Facilities, France.

Cervero, R., and C. D. Kang. 2011. Bus rapid transit impacts on land uses and land values in Seoul, Korea. Transport Policy 18(1): 102-116.

Currie, G. 2005. The demand performance of bus rapid transit. Journal of Public Transportation 8(1): 41-55.

Currie, G. 2006. Bus rapid transit in Australasia: Performance, lessons learned and futures. Journal of Public Transportation, 9(3): 1-22.

Currie, G., and A. Delbosc. 2011. Understanding bus rapid transit route ridership drivers: An empirical study of Australian BRT systems. Transport Policy 18(5): 755-764.

Delmelle, E. C., and I. Casas. 2012. Evaluating the spatial equity of bus rapid transit-based accessibility patterns in a developing country: The case of Cali, Colombia. Transport Policy 20: 36-46.

Demographia. 2014. Demographia world urban areas (built-up areas or world agglomerations). 10th Annual Edition (revised May 2014). Available at http://www. demographia.com/db-worldua.pdf (last accessed December 15, 2014).

Deng, T., and J. D. Nelson. 2010. The impact of bus rapid transit on land development: A case study of Beijing, China. World Academy of Science, Engineering and Technology 4(6): 1000-1010.

Deng, T., and J. D. Nelson. 2011. Recent developments in bus rapid transit: A review of the literature. Transport Reviews 31(1): 69-96.

Deng, T., and J. D. Nelson. 2012. The perception of bus rapid transit: A passenger survey from Beijing Southern Axis Line 1. Transportation Planning and Technology 35(2): 201-219.

Deng, T., and J. D. Nelson. 2013. Bus rapid transit implementation in Beijing: An evaluation of performance and impacts. Research in Transportation Economics 39: 108-113.

Diaz, R. B., and D. Hinebaugh (eds). 2009. Characteristics of bus rapid transit for decision-making (CBRT). National Bus Rapid Transit Institute for the Federal Transit Administration, Document FTA-FL-26-7109.2009.1.

Ernst, J. P. 2005. Initiating bus rapid transit in Jakarta, Indonesia. Transportation Research Record 1903: 20-26.

Federal Transit Administration (FTA). 2006. Bus rapid transit developments in China perspectives from research, meetings, and site visits in April 2006. Final Report for the U.S. Department of Transportation, Project Number: FTA-FL-26-7104.02.

Filipe, L. N., and R. Macario. 2013. A first glimpse on policy packaging for implementation of BRT projects. Research in Transportation Economics 39: 150-157.

Finn, B., O. Heddebaut, A. Kerkhof, F. Rambaud, O. Sbert-Lozano, and C. Soulas (eds). 2011. Buses with high level of service: Fundamental characteristics and recommendations 
for decision making and research, cost auction (TU0603). Final Report, October 2011.

Gilbert, A. 2008. Bus rapid transit: Is Transmilenio a miracle cure? Transport Reviews 28(4): 439-467.

Golotta, K., and D. Hensher. 2008. Why is the Brisbane bus rapid transit system deemed a success? Road and Transport Research 17(4): 3-16.

Gómez, J. 2004. Transmilenio: La joya de Bogotá, Transmilenio SA.

Gutierrez, L. 2010. TransMilenio in the world, in TransMilenio: 10 Years Transforming Bogotá. TRANSMILENIO S.A., Bogotá, December.

Hensher, D. 1999. A bus-based transitway or light rail? Continuing the saga on choice versus blind commitment. Road and Transport Research 8(3): 3-19.

Hensher, D. A., and T. F. Golob. 2008. Bus rapid transit systems: A comparative assessment. Transportation 35: 501-518.

Hess, D. B., and A. Bitterman. 2008. Bus rapid transit identity: An overview of current "branding" practice. Journal of Public Transportation 11(2): 19-42.

Hidalgo, D., P. Custodio, and P. Graftieaux. 2007. Critical look at major bus improvements in Latin America and Asia: Case studies of hitches, hic-ups, and areas for improvement. The World Bank, Urban Transport, Public Transport and Services, Bus-based Rapid Transit, January.

Hidalgo, D., and A. Carrigan. 2010. Modernizing public transportation, lessons learned from major bus improvements in Latin America and Asia. Washington DC: World Resources Institute.

Hidalgo, D., Y. Voukas, and A. Lopez. 2010. The macrobus system of Guadalajara: An evolved concept in BRT planning and implementation for medium capacity corridors. First NACTO BRT Workshop, April, New York.

Hidalgo, D., and L. Gutierrez. 2013. BRT and BHLS around the world: Explosive growth, large positive impacts and many issues outstanding. Research in Transportation Economics 39(1): 8-13.

Hidalgo, D., L. Pereira, N. Estupinan, and P. L. Jimenez. 2013. TransMilenio BRT system in Bogotá, high performance and positive impact-Main results of an ex-post evaluation. Research in Transportation Economics 39(1): 133-138.

Hodgson, P., S. Potter, J. Warren, and D. Gillingwater. 2013. Can bus really be the new tram? Research in Transportation Economics 39(1): 158-166.

Hsiao, S., J. Lu, J. Sterling, and M. Weatherford. 1997. Use of geographic information system for analysis of transit pedestrian access. Transportation Research Record 1604(1): 50-59.

Institute for Transportation and Development Policy (ITDP). 2014. The BRT Standard,2014 Edition. https://www.itdp.org/wp-content/uploads/2014/07/BRT-Standard-20141.pdf (last accessed December 1, 2014). 
Jarzab, J. T., J. Lightbody, and E. Maeda. 2002. Characteristics of bus rapid transit projects: An overview. Journal of Public Transportation 5(2): 31-46.

Jiang, Y., C. P. Zegras, and S. Mehndiratta. 2012. Walk the line:Station context, corridor type and bus rapid transit walk access in Jinan, China. Journal of Transport Geography 20(1): 1-14.

Kottenhoff, K. 2010. Bus rapid transit in Sweden. 3rd Transport Research Arena, June, Brussels, Belgium.

Lámbarry Vilchis, F. L., L. A. R. Tovar, and M. M. T. Flores. 2010. Institutional aspects on bus rapid transit systems: Implementation in Mexico City, Estado de Mexico and Leon Guanajuato. Journal of Management and Strategy 1(1): 93-109.

Lerner, J. 2013. Strategic vision and urban structure. Presentation at Mistra Urban Futures Meeting, Gothenburg, Sweden, December.

Levinson, H. S., S. Zimmerman, J. Clinger, and S. C. Rutherford. 2002. Bus rapid transit: An overview. Journal of Public Transportation 5(2): 1-30.

Levinson, H. S., S. Zimmerman, J. Clinger, S. C. Rutherford, R. L. Smith, J. Cracknell, and R. Soberman. 2003. Volume 1: Case studies in bus rapid transit. Transit Cooperative Research Program (TCRP) Report 90, Transportation Research Board, Washington, DC.

Lin, Z., and J. Q. Wu. 2007. Summary of the application effect of bus rapid transit at Beijing South-Centre corridor of China. Journal of Transportation Systems Engineering and Information Technology 7(4): 137-142.

Lindau, L. A., L. A. dos Santos Senna, O. Strambi, and W. C. Martins. 2008. Alternative financing for bus rapid transit (BRT): The case of Porto Alegre, Brazil. Research in Transportation Economics 22(1): 54-60.

Lindau, L. A., D. Hidalgo, and D. Facchini. 2010. Curitiba, the cradle of bus rapid transit. Built Environment 36(3): 274-282.

Mejia-Dugand, S., O. Hjelm, L. Baas, and R. A. Rios. 2013. Lessons from the spread of bus rapid transit in Latin America. Journal of Cleaner Production 50: 82-90.

Miller, M. A. 2009. Bus lanes/bus rapid transit systems on highways: Review of the literature. California PATH program. California PATH Working Paper UCB-ITSPWP-2009-1. Available at http://www.path.berkeley.edu/PATH/Publications/PDF/ PWP/2009/PWP-2009-01.pdf (last accessed December 15, 2014).

Muñoz, J. C., and A. Gschwender. 2008. Transantiago: A tale of two cities. Research in Transportation Economics 22(1): 45-53.

Perk, V., M. Mugharbel, and M. Catalá. 2010. Impacts of bus rapid transit stations on surrounding single-family home values: Study of East Busway in Pittsburgh, Pennsylvania. Transportation Research Record 2144(2): 72-79. 
Perk, V., S. Bovino, M. Catalá, S. Reader, and S. Ulloa. 2013. Silver Line bus rapid transit in Boston, Massachusetts impacts on sale prices of condominiums along Washington Street. Transportation Research Record 2350: 72-79.

Pucher, J., Z. Peng, N. Mittal, Y. Zhu, and N. Korattyswaroopam. 2007. Urban transport trends and policies in China and India: Impacts of rapid economic growth. Transport Reviews 27(4): 379-410.

Rabinovitch, J., and J. Leitman. 1996. Urban planning in Curitiba. Scientific American 274: 26-33.

Satiennam, T., A. Fukuda, and R. Oshima. 2006. A study on the introduction of bus rapid transit system in Asian developing cities-A case study on Bangkok metropolitan administration project. IATSS Research 30(2): 59-69.

Stojanovski, T. 2013. Bus rapid transit (BRT) and transit-oriented development (TOD): How to transform and adjust the Swedish cities for attractive bus systems like BRT? What demands BRT? Licentiate Thesis, KTH Royal Institute of Technology, Stockholm, Sweden.

Susilo, Y. O., T. B. Juwono, W. Santosa, and D. Parikesit. 2007. A reflection of motorization and public transport in Jakarta metropolitan area: Lessons learned and future implications towards better transportation development in developing countries. Journal of Eastern Asia Society for Transportation Studies 7: 299-313.

Trafikverket. 2014. Available at http://www.trafikverket.se/ (last accessed December 1, 2014).

Weinstock, A., W. Hook, M. Replogle, and R. Cruz. 2011. Recapturing global leadership in bus rapid transit: A survey of select U.S. Cities. A Publication of the Institute for Transportation and Development Policy, New York.

Wirasinghe, S. C., L. Kattan, M. M. Rahman, J. Hubbell, R. Thilakaratne, and S. Anowar. 2013. Bus rapid transit-A review. International Journal of Urban Sciences 17: 1-31.

Wöhrnschimmel, H., M. Zuk, G. Martinez-Villa, J. Ceron, B. Cardenas, L. Rojas-Bracho, and A. Fernadez-Bremauntz. 2008. The impact of a bus rapid transit system on commuters' exposure to Benzene, $\mathrm{CO}, \mathrm{PM}_{2.5}$ and $\mathrm{PM}_{10}$ in Mexico City. Atmospheric Environment 42(35): 8194-8203.

Wright, L., and W. Hook. 2007. Bus Rapid Transit Planning Guide. Institute for Transportation and Development Policy, New York.

Yazici, A. M., H. S. Levinson, M. Ilicali, N. Camkesen, and C. Kamga. 2013. A bus rapid transit line case study: Instabul's Metrobus system. Journal of Public Transportation 16(1): 153-177.

Yunita, R. 2008. TransJakarta: Putting on lipstick while running to catch the bus. Sustainable Transport 20: 5-7.

Zimmerman, S., and H. S. Levinson. 2004. Vehicle selection for BRT: Issues and options. Journal of Public Transportation 7(1): 83-103. 
Zingale, N. C., and D. Riemann. 2013. Coping with shrinkage in Germany and the United States: A cross-cultural comparative approach toward sustainable cities. Urban Design International 18: 90-98.

\section{About the Authors}

AleXandros Nikitas (alexandros.nikitas@chalmers.se) has a Ph.D. in Transportation from the University of the West of England, UK. He is a Senior Academic Researcher working in the field of urban futures and transportation for the Division of Design \& Human Factors, which is part of the Department of Product and Production Development at Chalmers University of Technology in Gothenburg, Sweden.

MARIANNE KARLSSON (mak@chalmers.se) is Professor (chair) in Human Factors Engineering and Head of the Division of Design \& Human Factors at the Department of Product and Production Development of Chalmers University of Technology in Gothenburg, Sweden. 